\title{
CREEP OF COLUMNAR-GRAINED ICE AT LOW STRESS
}

\author{
by \\ L. W. Gold \\ (Division of Building Research, National Research Council Canada, Ottawa, Ontario K1A OR6, \\ Canada)
}

\begin{abstract}
An investigation was undertaken of the creep of columnar-grained ice under constant compressive stresses of 98 and $59 \mathrm{kPa}$ in order to extend the observed relationship between strain-rate and stress further into the low-stress region. Stress was applied perpendicular to the long direction of the grains. Observations were made for temperatures between -5 and $-40^{\circ} \mathrm{C}$. The steady-state creep rate for secondary creep was not yet attained for strain of $1.4 \%$ and stress of $98 \mathrm{kPa}$. An initial yield was observed at that stress in the strain range of 0.2 to $0.3 \%$, similar to that seen at higher stress. The observations showed that the strain-rate tended to a linear dependence on stress below $49 \mathrm{kPa}$ and that more than one dislocation process with different values for the stress exponent may contribute to the strain at higher stresses. An activation energy of $63 \mathrm{~kJ} \mathrm{~mol}^{-1}$ was consistent with the observed temperature dependence of the strain-rate. Straining ice to a given strain under a stress of about $0.3 \mathrm{MPa}$ and then reducing the load may be a convenient way to study the stress, strain and temperature dependence of the strain-rate at low stress.
\end{abstract}

\section{INTRODUCTION}

Observations on the stress dependence of the creep rate of columnar-grained ice have been confined to a fairly narrow range of compressive stress. The upper limit is determined by the rapid breakdown of the ice structure by crack formation for stress greater than about $3 \mathrm{MPa}$, and the lower limit, about $200 \mathrm{kPa}$, by the length of time required to strain the ice more than $1 \%$. At the lower end, it takes more than 50 days to deform polycrystalline ice at $-10^{\circ} \mathrm{C}$ beyond the initial transient or primary creep range.

It is considered that the viscous creep of ice over this stress range is controlled by the movement of basal-plane dislocations out of their slip plane in the grain-boundary region. This model predicts a power-law dependence of the strain-rate on stress. It has been postulated that for small stress (less than $100 \mathrm{kPa}$ ) the Nabarro-Herring process should control the creep behaviour, resulting in a linear dependence of strain-rate on stress.

A creep test was carried out at a stress of $98 \mathrm{kPa}$ to a strain of $2 \%$ to extend the observed relationship for the stress dependence of the strainrate further into the low-stress range. This required that the load be maintained for $35500 \mathrm{~h}$ (slightly over four years). A second experiment was then carried out to determine if the strain-rate for a specimen strained to about $1.4 \%$ under a constant compressive stress of $300 \mathrm{kPa}$ was the same as for the first specimen at that strain when the stress was reduced to $98 \mathrm{kPa}$. When this was found to be the case, the stress was reduced to $49 \mathrm{kPa}$. This paper reports the results of these measurements.

\section{EXPERIMENTAL. PROCEDURE}

The specimens were made from columnar-grained, type S2 ice prepared in a manner described by Gold $(1965,1972[b])$. For this type of ice the crystallographic $\mathrm{C}$-axis tends to be in the plane perpendicular to the long direction of the columnar grains and to have a random orientation. A characteristic of this ice, often the principal one in ice covers, is that the deformation is essentially two-dimensional for stress applied perpendicular to the long direction of the grains, with the strain in the plane normal to the direction of the grains being much greater than that in the perpendicular direction.

Because of this symmetry, rectangular specimens $25 \times 10 \times 5 \mathrm{~cm}$ in size, prepared with a milling machine, were used. The long direction of the grains was perpendicular to the $25 \times 10 \mathrm{~cm}$ face. Average grain size increased from about $2.5 \mathrm{~mm}$ at one face to $3.5 \mathrm{~mm}$ at the other. After the specimens had been wrapped in a polyvinyl film to prevent sublimation, loads were applied to the $10 \times 5 \mathrm{~cm}$ ends through metal platens using a dead-weight lever system. Total deformation was measured using two dial gauges attached to the upper platen on either side of the specimen. The divisions on the gauge dial corresponded to a displacement of $2.5 \times 10^{-4} \mathrm{~cm}$ or a strain of about $2.5 \times 10^{-5}$

The tests were carried out in a room for which the temperature could be controlled with an accuracy of $0.1^{\circ} \mathrm{C}$ over long periods of time. Observations were made for temperatures between -5 and $-40^{\circ} \mathrm{C}$.

\section{RESULTS}

The time dependence of the strain is presented in Figure 1 for the first test and in Figure 2 for the second. Times of temperature and stress changes and features of interest are indicated by numbered lines. The temperature and stress changes or other reinarks corresponding to these times are presented in Table I for specimen 1. It was found that the strain-rate, also shown in Table I, was essentially constant over the relatively long periods between lines. In preparing Figure 1 and Table I, strains due to a change in temperature were ignored.

The change in strain-rate with strain for the long-term test is presented in Figure 3. It was found that the strain-rate had a maximum in the strain 


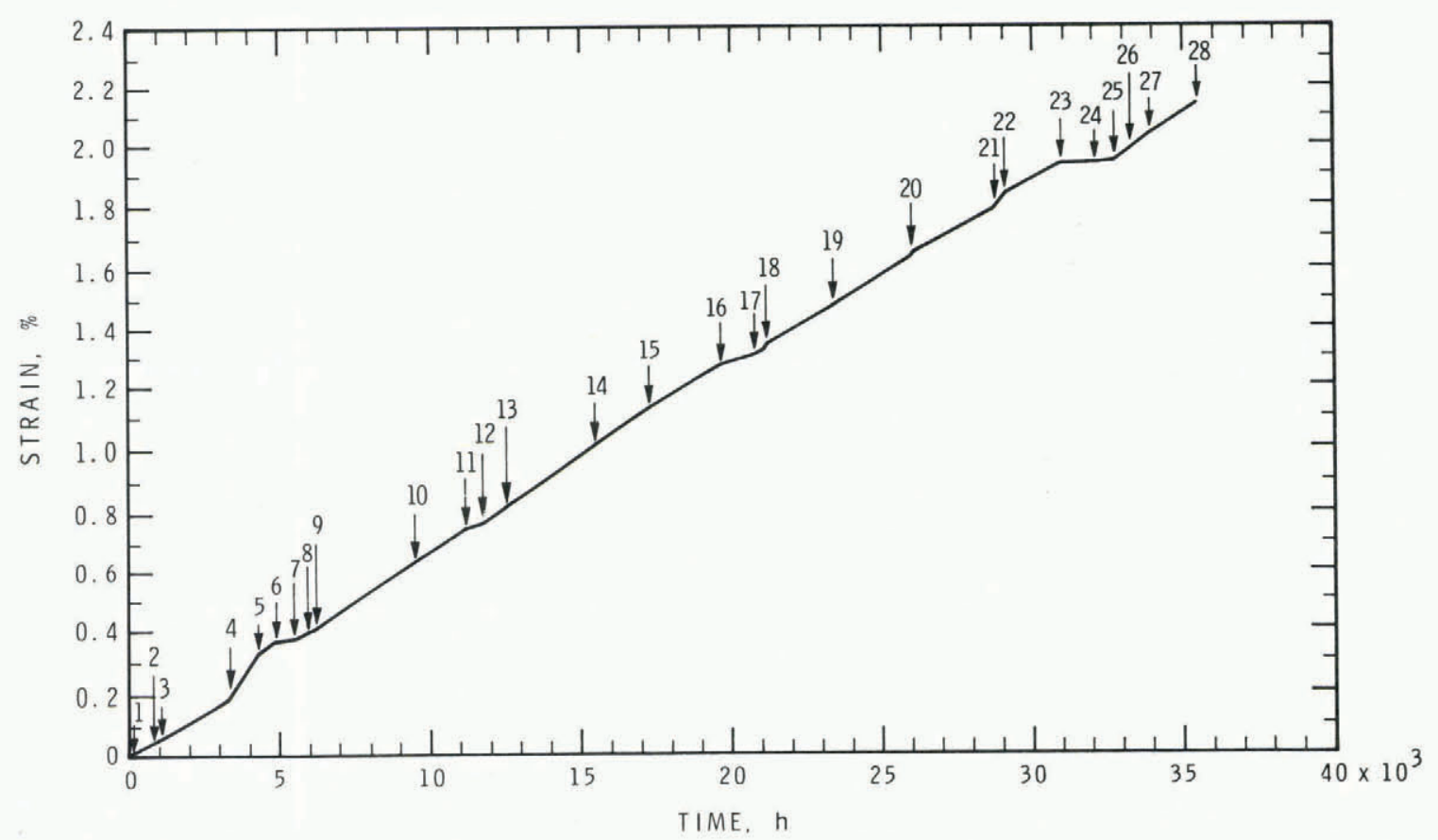

Fig.1. Time dependence of strain for stress of $98 \mathrm{kPa}$ and various temperatures. See Table I for information relevant to numbered lines.

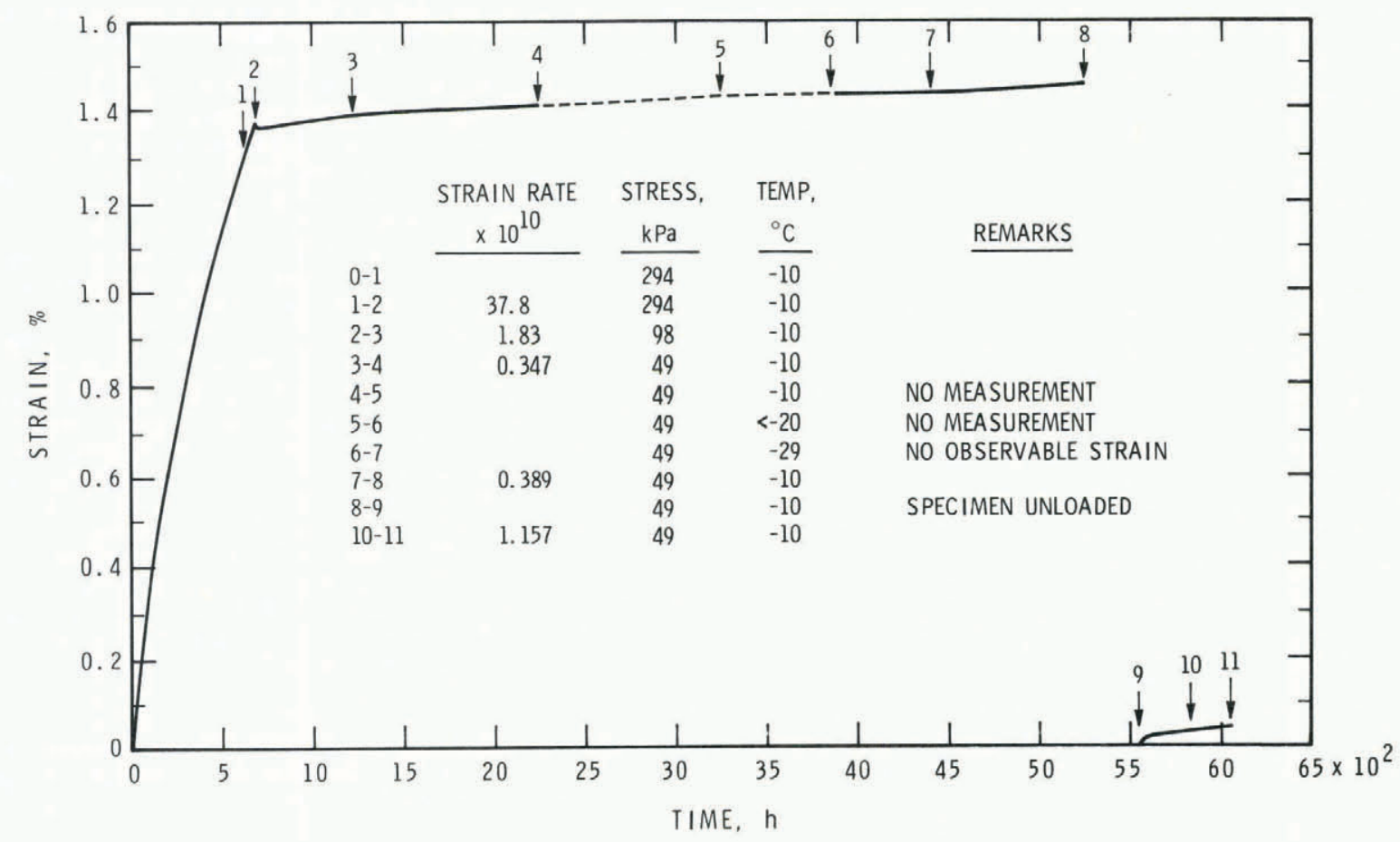

Fig.2. Time dependence of strain for specimen 2.

range of 0.2 to $0.3 \%$ as observed at higher stress (Krausz 1963, Gold 1965, 1972[a]). Similar behaviour was observed for granular ice by Mellor and Cole (1982), who used a very stiff testing machine. The numbers above each plotted point identify the strainrate and strain range in Table $I$.

Some interesting and potentially significant irregularities were noticed in the long-term creep behaviour (see Figs. 1 and 3 ). The high creep rate between lines 12 and 13 plotted at a strain of
$0.79 \%$ followed an increase in temperature from -20 to $-10^{\circ} \mathrm{C}$. Although a similar increase was not observed immediately after the period between lines 16 and 17 at $-19.8^{\circ} \mathrm{C}$, there were rapid increases in strain at lines 18,19 and 20 , as well as a slight tilting at line 20 (Table I). These rapid changes in strain, which occurred over 2- to 10-day periods, were registered by both dial gauges. The strain-rate between positions 19 and 20, plotted at a strain of $1.56 \%$, was also greater than would have been expected 
TABLE I. INF(IRMATION ON TIME, TEMPERATURE, STRAIN AND STRAIN-RATE FOR SPECIMEN 1 (stress is $98 \mathrm{kPa}$ )

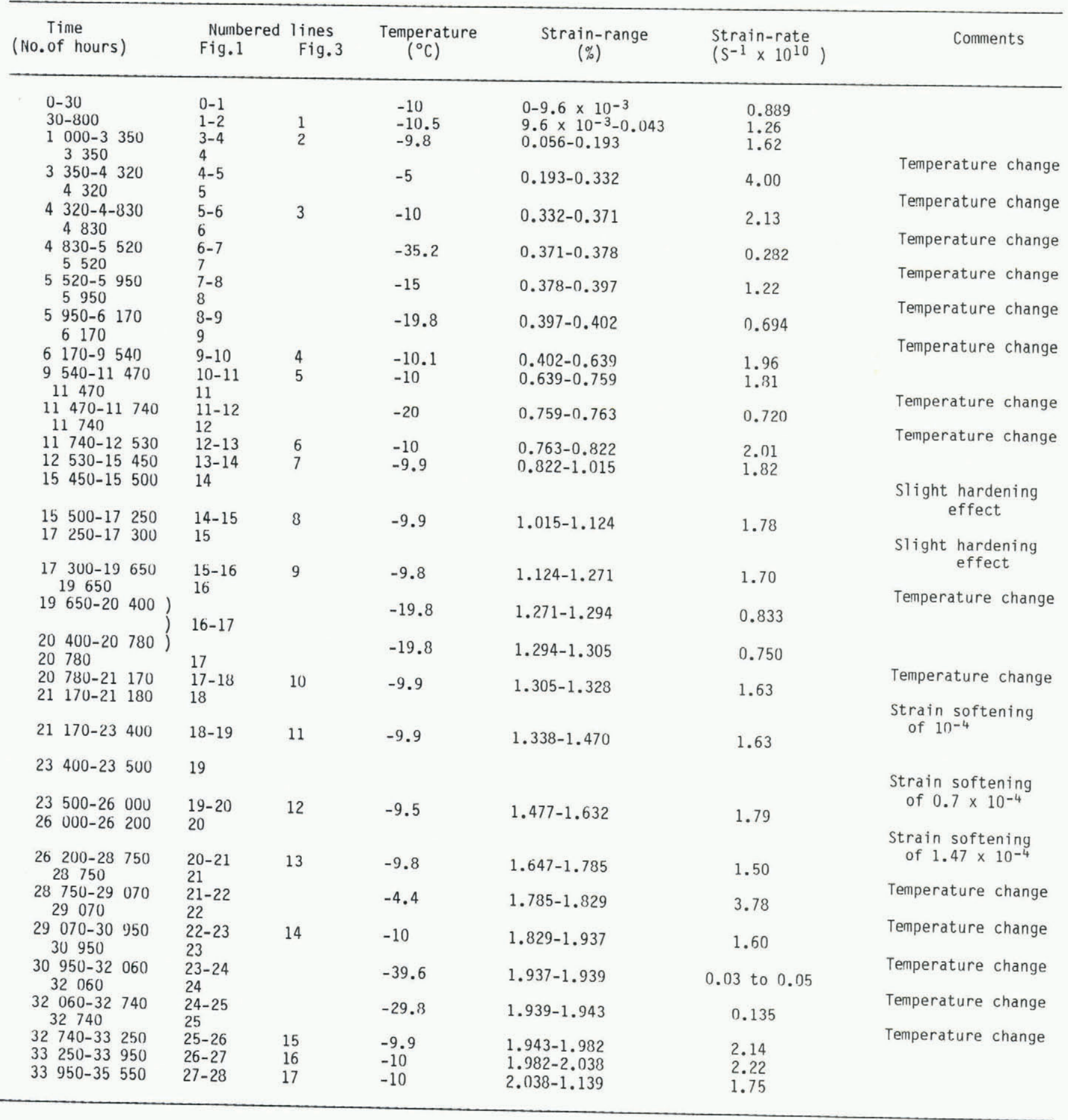

from the earlier trend. It appeared that in the strain range of $1.3 \%$ to $1.8 \%$ the ice was going through periods of structural instability. The markedly large strain-rates plotted at strains of 1.97 and $2.03 \%$ occurred at $-10^{\circ} \mathrm{C}$, immediately after a period at $-39.6^{\circ} \mathrm{C}$ and at $-29.8^{\circ} \mathrm{C}$.

In the second test the specimen was unloaded at about $5250 \mathrm{~h}$ and reloaded at $5540 \mathrm{~h}$. It was found that even by $6050 \mathrm{~h}$ the strain-rate still had not decreased to its value between lines 6 and 7 .

In Figure 4 are plotted the results obtained on the stress dependence of the strain-rate for stress up to $0.98 \mathrm{MPa}$, temperature of $-10^{\circ} \mathrm{C}$ and strain of 1.4 to $1.5 \%$. The observations at stresses of 0.59 , 0.78 and $0.98 \mathrm{MPa}$ are the average of six tests (Gold 1972[a]). The initial yield behaviour over the strain range of 0.10 to $0.30 \%$ was observed in all cases.

The observations for stress $>0.3 \mathrm{MPa}$ indicate 


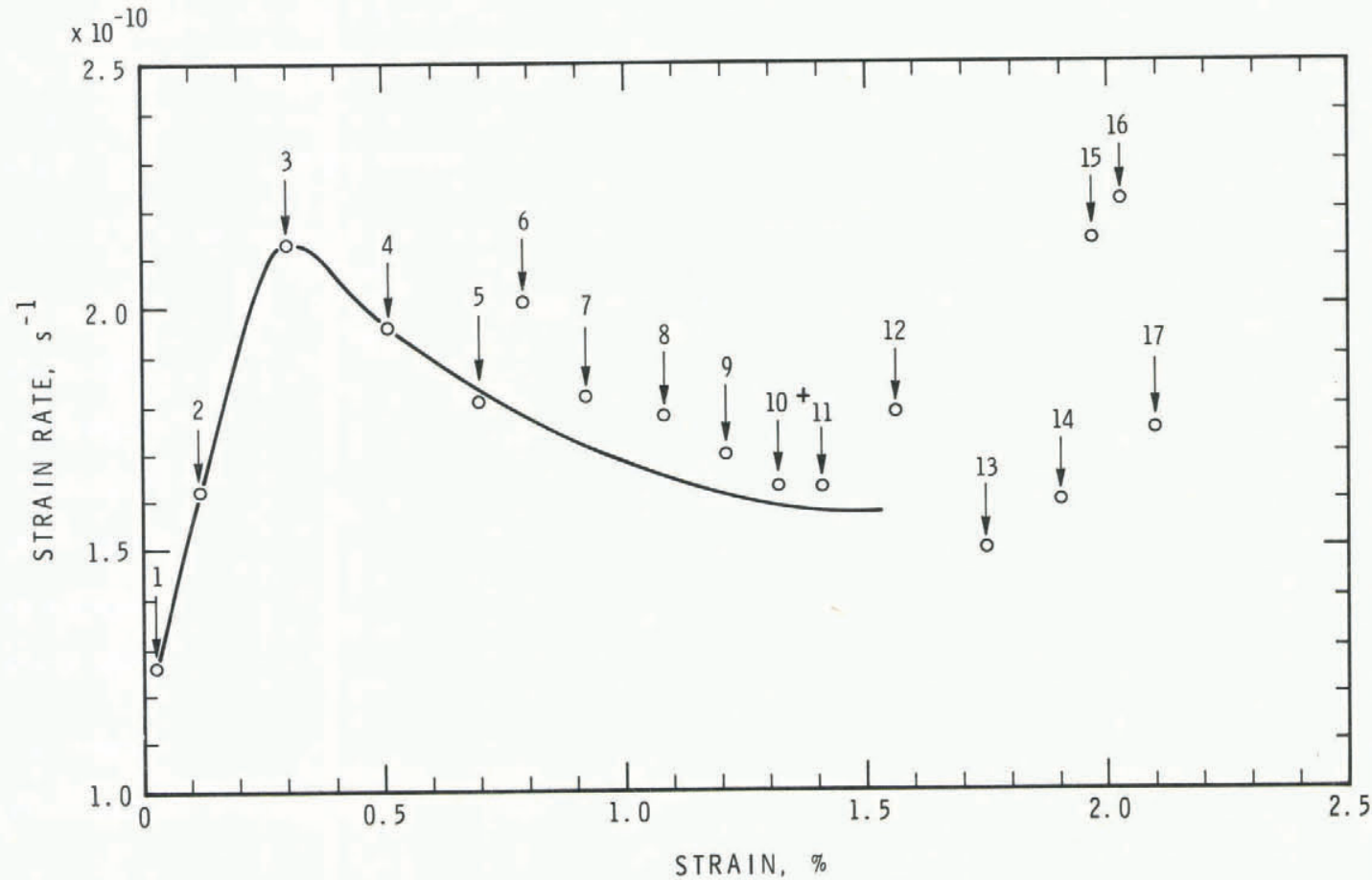

Fig.3. Strain dependence of strain-rate. o: specimen 1, +: specimen 2, T: $-10^{\circ} \mathrm{C}$. See Table I for information relevant to numbered lines.

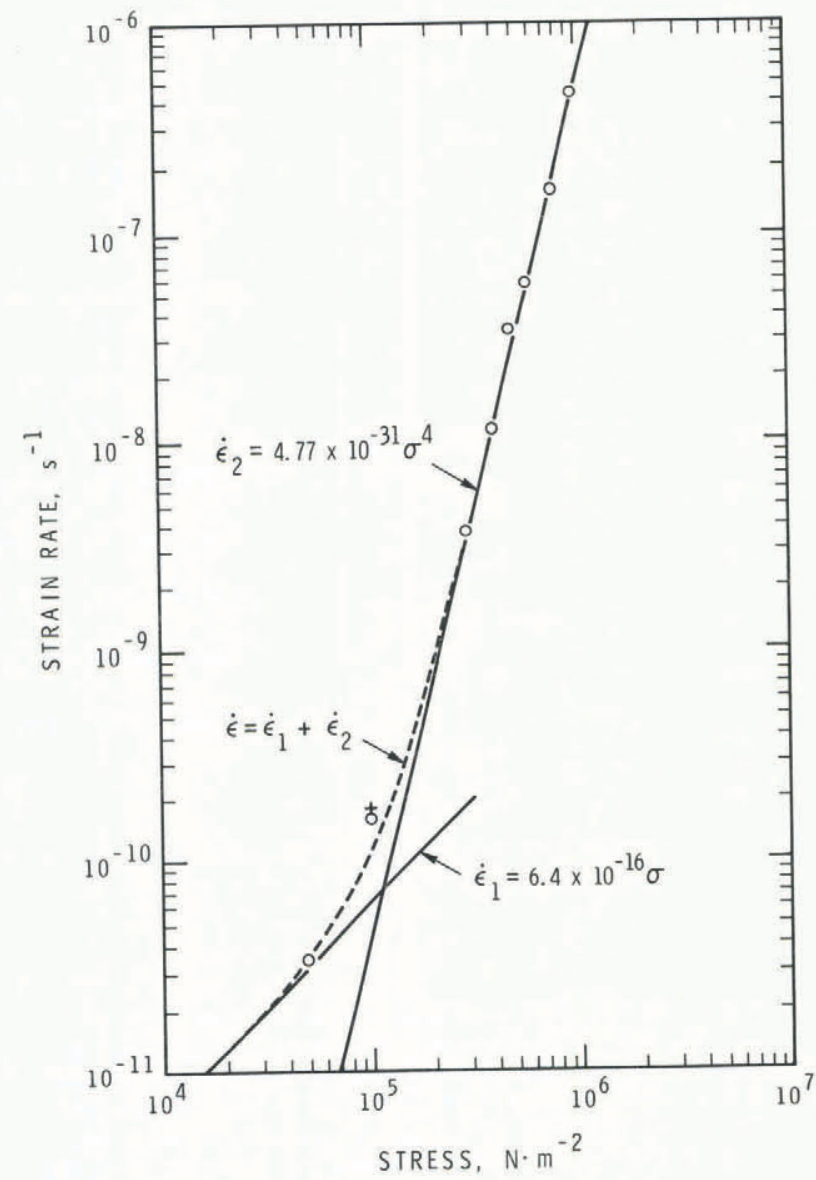

Fig.4. Stress dependence of strain-rate. $\mathrm{T}:-10^{\circ} \mathrm{C}$, strain: 1.4 to $1.5 \%$. the usual power-law dependence, i.e.

$$
\dot{\varepsilon}=A \sigma^{n} \text {, }
$$

where $\dot{\varepsilon}$ is the strain-rate, $\sigma$ the stress, and $A$ and $n$ are constants. The value of $n$ was found to be 4 . It was assumed that the Nabarro-Herring process controls the stress dependence of the strain-rate at low stress and that

$$
\dot{\varepsilon}=A_{1} \sigma+A_{2} \sigma^{4} \text {. }
$$

The values of $A_{1}$ and $A_{2}$ were determined by the observations for $\sigma=50 \mathrm{kPa}$ and $0.4 \mathrm{MPa}$. The result is plotted in Figure 4; the total strain is shown as the dashed line.

For high homologous temperatures, the stress

dependence of the strain-rate is sometimes expressed in general by an equation of the form

$$
\dot{T} \dot{\varepsilon}=\frac{A D \sigma^{n}}{d^{m}},
$$

where $T$ is the temperature in $K$, $d$ the grain size, and $D$ the coefficient of diffusion given by

$$
D=D_{0} \exp \left(\frac{-Q}{R T}\right) \text {. }
$$

$D_{0}$ and $m$ are constants, $R$ is the gas constant, and Q. the activation energy (Langdon 1973). The product $\mathrm{T} \dot{\varepsilon}$ is plotted in Figure 5 against $1 / T$ for the longterm test. A line corresponding to $Q=63 \mathrm{~kJ} \mathrm{~mol}^{-1}$ is drawn through the point

$\dot{T \varepsilon}=4.5 \times 10^{-8} \mathrm{Ks}^{-1}$ and $1 / \mathrm{T}=3.8 \times 10^{-3} \mathrm{~K}^{-1}$.

It can be seen that this value for $Q$ is consistent with the observations.

\section{DISCUSSIUN}

An interesting feature of the creep behaviour of columnar-grained ice is that the steady-state or secondary creep rate appears to be a minimum that 


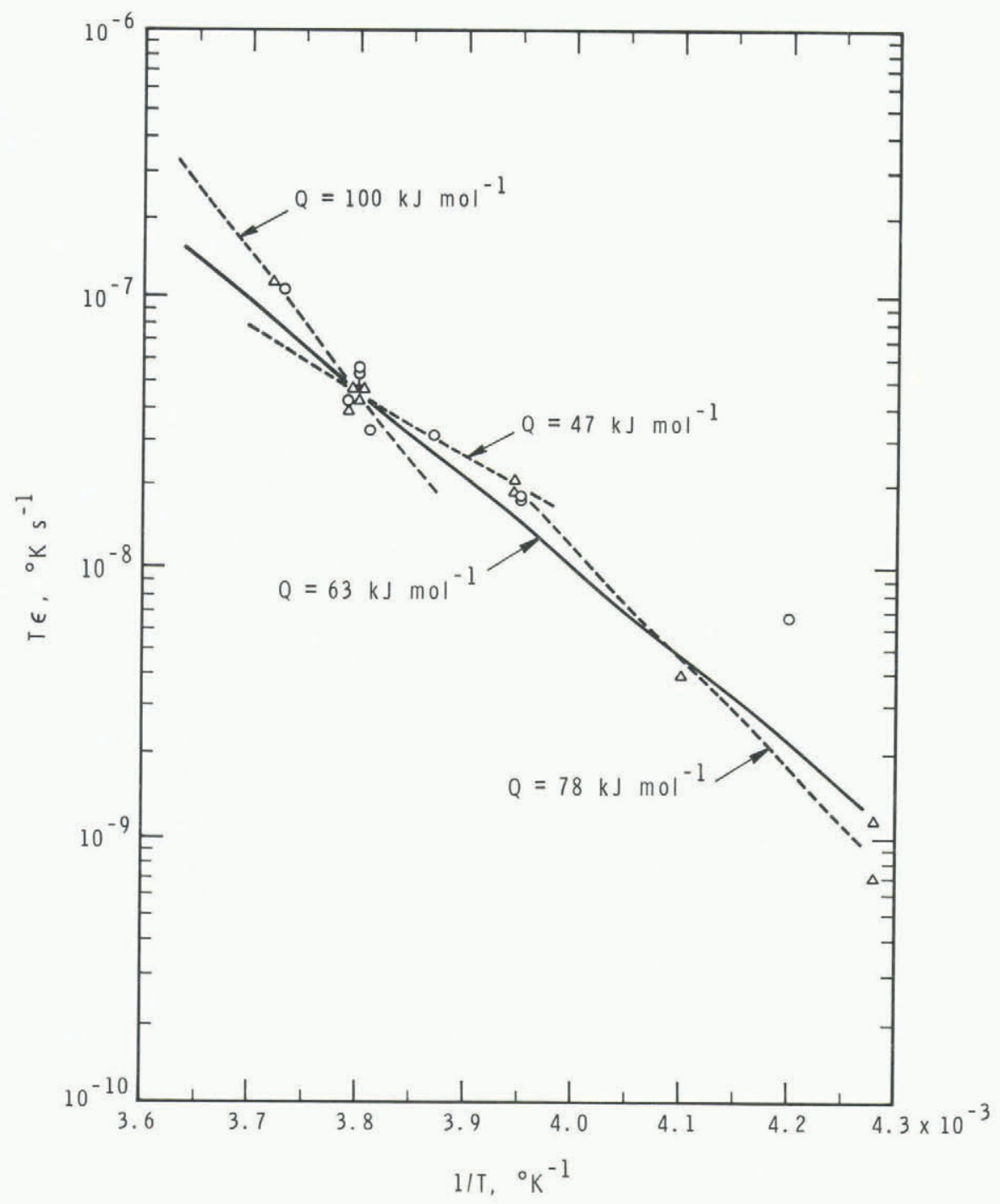

Fig.5. Dependence of $\dot{T} \dot{\varepsilon} K^{-1}$ on $1 / T K^{-1}$. stress: $98 \mathrm{kPa}, 0$ : strain $<1 \%, \Delta$ : strain $>1 \%$, + : specimen 2.

occurs in a relatively narrow range of strain. In the present study, for stress between 0.1 and $1 \mathrm{MPa}$ and temperature of $-10^{\circ} \mathrm{C}$, this range begins at about 1.4 to $1.5 \%$. Mellor and Cole (1982) found that the minimum for granular ice and stress between 0.8 and $3.67 \mathrm{MPa}$ occurred at a strain of about $1 \%$. The fact that the strain at which the minimum occurs is relatively constant suggests that the functional form of the strain dependence of the effective stress controlling the deformation process(es) is dependent primarily on the strain. It also indicates that structural changes due to the movement of dislocations, for example, may be relatively insensitive to stress levels below those at which cavity and crack formation occurs.

This behaviour also suggests that the stress dependence of the strain-rate at low stress might be be studied conveniently in the secondary creep region by straining to this region initially using a higher stress. The relatively close agreement between the strain-rates at $1.4 \%$ and stress of $98 \mathrm{kPa}$ found for the two load histories in the present study bear this out (see Fig. 3).

Caution, however, must be used with this procedure. The information to date shows that for columnargrained ice the position of the maximum strain-rate during the initial yield moves from 0.25 to $0.15 \%$ strain when the stress is decreased from 0.9 to
$0.6 \mathrm{MPa}$ and returns to about $0.3 \%$ at $98 \mathrm{kPa}$. Figure 4 also provides evidence that at very low stress a creep process of the Nabarro-Herring type is dominant. This process may not bring about the structural changes that are associated with deformation processes at higher stress. At a stress of $0.3 \mathrm{MPa}$ these processes were observed to cause grain-boundary migration and polygonization in the grain-boundary region, particularly at triple points, for strain less than $1 \%$.

None of the dislocation mechanisms listed by Langdon (1973), which might be applicable to ice, had a stress exponent of 4 . This, plus the fact that the calculated curve in Figure 4 underestimates the strain observed at $0.1 \mathrm{MPa}$, indicates that there may be at least three deformation processes for ice. One of the processes may depend on grain size, such as grain-boundary sliding due to a dislocation process with a stress exponent of 2 , and might thus explain the difference observed for the exponent for granular ice (about 3) and columnar-grained, type S2 ice (about 4). Granular ice has a significantly larger grain-boundary area than columnar-grained ice of the same nominal grain size.

Gold (1963) attributed the maximum in the strainrate during the initial transient creep to the development of modes of deformation in previously 
undeformed ice. The initiation of these modes was considered to be due to the stresses associated with the pile-up of dislocations in the grain-boundary region and to the limited degrees of freedom for deformation of individual grains of ice. These modes included slip on the basal and non-basal planes, formation of low-angle boundaries and kink bands, grain-boundary migration, polygonization, cavity forination and, for stress greater than about $0.5 \mathrm{MPa}$, crack formation. The maximum in the strain-rate shown in Figure 3 for a stress of $98 \mathrm{kPa}$ indicates that dislocation processes are still significant at this stress level.

Morland and Spring (1981) have modelled mathematically the minimum in the secondary creep rate assuming strain-rate to be a function of stress, stress rate and strain acceleration. Little attention has been given, however, to the effects of structural changes on the mathematical description of the deformation behaviour before, during and after the minimum, particularly for previously undeformed ice. The observations on columnar-grained ice have clearly shown that these changes are strongly straindependent during the initial transient or primary creep stage and introduce a dependence on strain history that may be very difficult to establish explicitly. For example, observations have shown that the yield effect during the initial transient creep is not observed on reloading after a period of recovery (Krausz 1963, Gold 1965). Smith and Morland (1981) concluded, after attempting to fit both a 3- and a 4-term polynomial stress function to published data on the minimum secondary creep rate, that "it is clear that there is no real consistency between the various data, with normalized strainrates at fixed stress varying by a factor of $3^{\prime \prime}$. This variability may not be present for those situations for which ice has been extensively deformed, for example, in glaciers. In most engineering problems, however, ice has had little or no previous deformation and the strain is usually less than $1 \%$. It may be necessary to accept that there is no simple, single relation that satisfactorily describes the first $2 \%$ strain for ice under all conditions.

Although the observations of the temperature dependence of $T \varepsilon$ shown in Figure 5 are consistent with an activation energy of $63 \mathrm{~kJ} \mathrm{~mol}^{-1}$, this may be more apparent than real, as shown by the dashed lines. The range of $Q$ defined by these lines is 47 to $100 \mathrm{~kJ} \mathrm{~mol}-1$. Most observations of the activation energy for polycrystalline ice lie in this range. It is possible that the deformation processes in ice have different activation energies; consequently their relative contribution and accompanying structural changes would be temperature-dependent.

This is consistent with the conclusions arrived at by Smith and Morland (1981) that "present data do not predict a single temperature-dependent rate factor". If this is the case, it would be expected that it would take time after a change in temperature to establish the expected strain-rate for given stress, strain and temperature. That is, the deformation behaviour following a change in temperature may depend not only on the strain but on the previous temperature condition as well.

\section{CONCLUSIONS}

The steady-state creep rate of columnar-grained, type S2 ice at $-10^{\circ} \mathrm{C}$ is not attained before a strain of $1.4 \%$. Straining the ice relatively rapidly to a given strain and then reducing the load may be a convenient way to study the stress, strain and temperature dependence of the strain-rate for low stresses. Observations of this dependence for stress down to $50 \mathrm{kPa}$ indicate that a linear dependence of the strain-rate on stress exists below this level at $-10^{\circ} \mathrm{C}$ and that more than one dislocation process with different values for the stress exponent may control the deformation behaviour at higher stresses. Type S2 columnar-grained ice has an initial yield in the strain range of 0.2 to $0.3 \%$ when deformed under a constant compressive load of $0.1 \mathrm{MPa}$ applied perpendicularly to the long direction of the grains, which shows that dislocation processes are still significant at this stress. Although a value of $63 \mathrm{~kJ} \mathrm{~mol}^{-1}$ for the activation energy is consistent with the observed temperature dependence of the strain rate for a stress of $98 \mathrm{kPa}$, the observations were not sufficiently definitive to rule out the possibility that the effective activation energy may be temperature-dependent.

\section{REFERENCES}

Gold L W 1963 Deformation mechanisms in ice. In Kingery WD (ed) Ice and snow. Cambridge, MA, MIT Press: $8-27$

Gold L W 1965 The initial creep of columnargrained ice. Part I. Observed behavior. Canadian Journal of Physics 43(8): 1414-1422

Gold L W 1972[a] The failure process in columnargrained ice. Canada. National Research Council. Division of Building Research. Technical Paper 369

Gold L W 1972[b] The process of failure of columnargrained ice. Philosophical Magazine Eighth Ser 26(2): 311-328

Krausz A S 1963 The creep of ice in bending. Canadian Journal of Physics 41(1): 167-177

Langdon T G 1973 Creep mechanisms in ice. In Whalley E, Jones S J, Gold L W (eds) Physics and chemistry of ice. Ottawa, Royal Society of Canada: 356-361

Mellor M, Cole D M 1982 Deformation and failure of ice under constant stress or constant strain-rate. Cold Regions Science and Technology 5(3): 201-219

Morland L W, Spring U 1981 Viscoelastic fluid relation for the deformation of ice. Cold Regions Science and Technology 4(3): 255-268

Smith G D, Morland L W 1981 Viscous relations for the steady creep of polycrystalline ice. Cold Regions Science and Technology 5(2): 141-150 